\title{
Nanoindentation and atomic force microscopy measurements on reactively sputtered $\mathrm{TiN}$ coatings
}

\author{
HARISH C BARSHILIA and K S RAJAM* \\ Surface Engineering Division, National Aerospace Laboratories, Bangalore 560 017, India
}

MS received 19 February 2003; revised 29 December 2003

\begin{abstract}
Titanium nitride (TiN) coatings were deposited by d.c. reactive magnetron sputtering process. The films were deposited on silicon (111) substrates at various process conditions, e.g. substrate bias voltage $\left(V_{B}\right)$ and nitrogen partial pressure. Mechanical properties of the coatings were investigated by a nanoindentation technique. Force vs displacement curves generated during loading and unloading of a Berkovich diamond indenter were used to determine the hardness $(H)$ and Young's modulus $(Y)$ of the films. Detailed investigations on the role of substrate bias and nitrogen partial pressure on the mechanical properties of the coatings are presented in this paper. Considerable improvement in the hardness was observed when negative bias voltage was increased from 100-250 V. Films deposited at $\left|V_{B}\right|=250 \mathrm{~V}$ exhibited hardness as high as $3300 \mathrm{~kg} / \mathrm{mm}^{2}$. This increase in hardness has been attributed to ion bombardment during the deposition. The ion bombardment considerably affects the microstructure of the coatings. Atomic force microscopy (AFM) of the coatings revealed fine-grained morphology for the films prepared at higher substrate bias voltage. The hardness of the coatings was found to increase with a decrease in nitrogen partial pressure.
\end{abstract}

Keywords. TiN coatings; reactive magnetron sputtering; mechanical properties; nanoindentation measurements; atomic force microscopy.

\section{Introduction}

Titanium nitride (TiN) coatings produced by physical vapour deposition (PVD) have been extensively studied since the beginning of 1980s. The application of titanium nitride films on high-speed steels with different PVD techniques is today a well-established technology. Tools coated with TiN show increase in the tool-life by several folds compared to uncoated tools. It is known that TiN films show different microstructural properties depending upon the deposition processes and deposition conditions (Petrov et al 1989; Carney and Durham 1999; Chen et al 2001). In the case of reactively sputtered TiN coatings, nitrogen partial pressure plays an important role in determining the mechanical properties (Musil et al 1986; Sproul et al 1989; Yang et al 2000). Also, it is well known that ion bombardment of the growing TiN film modifies the microstructure of the coatings significantly (Hultman et al 1987). In general, to enhance the mechanical properties of TiN coatings, a negative bias voltage $\left(V_{\mathrm{B}}\right)$ is applied to the substrate during deposition (Takahashi et al 2000; Zhengyang et al 2000; Zhitomirsky et al 2000).

Microhardness measurements on TiN coatings are well documented (Sproul et al 1989; Takadoum and Bennani 1997). Since these coatings are typically a few $\mu \mathrm{m}$ thick, accurate measurements of the mechanical properties by

\footnotetext{
*Author for correspondence
}

microindentation technique becomes very difficult and the data are easily affected by the substrate. This is mainly because microindentation limits the maximum depth of indentation, meaning that depths less than 1-2 $\mu \mathrm{m}$ make the indentation too small for measurement by conventional light microscopes. In the case of very thin films (micron and sub-micron), their intrinsic hardness becomes meaningful only if the influence of the substrate material can be eliminated (Randall et al 1998). Thus, the indentation depth should not exceed about one-tenth of the total coating thickness. Applied loads in the range $0 \cdot 5-50 \mathrm{mN}$ are desirable if the indentation depths are to remain in the nanometer range (Tsui and Pharr 1999). Recently, a nanoindentation technique has been developed (Oliver and Pharr 1992; Randall et al 1998; Tsui and Pharr 1999) in which continuous measurement of force and displacement is carried out as an indenter, of known geometry, is pressed into the sample material. With force and displacement resolution in the ranges $5 \mu \mathrm{N}$ and $0.3 \mathrm{~nm}$, respectively, it is possible to produce load displacement curves representative of the material response in terms of hardness and Young's modulus.

Though mechanical properties of TiN coatings are well documented in the literature, in the present study we have attempted to perform nanoindentation measurements more accurately on the films deposited at various process conditions. Parameters such as nature of substrate and surface roughness, which critically affect the nanoindentation data, have been taken into consideration while performing 
the indentation measurements. Atomic force microscopy (AFM) has been used to image the surfaces of as-deposited TiN coatings. Attempts have been made to correlate the effects of ion current and surface morphology (e.g. fine or coarse-grained structure) on the mechanical properties of TiN coatings.

\section{Experimental}

TiN coatings were deposited on silicon (111) substrates using a reactive d.c. magnetron sputtering system the details of which are described elsewhere (Barshilia and Rajam 2002, 2003). Pure titanium with a purity of $99.995 \%$ (SputterMet, Inc.) was used as the sputtering target. The diameter of the target was 3 inches. The target was sputtered in high purity argon (99.999\%) and nitrogen (99.999\%) plasma. The films were deposited on mirror polished silicon substrates (area $=15 \times 15 \mathrm{~mm}^{2}$ ). Prior to deposition, the substrates were cleaned chemically followed by ion bombardment in argon plasma for $30 \mathrm{~min}$. TiN films were deposited at an operating pressure of about $3 \cdot 0 \times 10^{-3}$ mbar. The film thickness was about $2 \mu \mathrm{m}$. Approximately $1 \mu \mathrm{m}$ thick titanium interlayer was incorporated between the substrate and the film to achieve better adhesion. A series of films were deposited at various substrate bias voltages $(0-250 \mathrm{~V})$ and nitrogen flow rates $(0 \cdot 6-3 \mathrm{sccm})$. The sputtering power $(220$ watts $)$ and argon flow rate $(17 \mathrm{sccm})$ were kept constant for all the experiments. No external substrate heater was used. Under these conditions, the plasma bombardment increased the substrate temperature to $\sim 130^{\circ} \mathrm{C}$ during the deposition. The growth rate for TiN coatings was $\sim 0.82 \mu \mathrm{m} / \mathrm{h}$.

The nanoindentation measurements were performed with an instrument consisting of a nanohardness tester (CSEM Instruments) and an integrated optical (Nikon)/ atomic force microscope (surface imaging systems). The nanohardness tester consists of two distinct components-a measuring head for performing indentation and an optical microscope for selecting a specific sample location prior to the indentation and for checking the location of the imprint after indentation. Both components are directly linked by a positioning system, which allows movements in $X-Y$ axes. The main advantage of this instrument is its differential measurement of the sample surface made possible by a sapphire reference ring, which remains in contact with the sample during the loading/unloading cycle, thus giving exact position of the indenter tip relative to the sample surface. The displacement resolution was $0.3 \mathrm{~nm}$ and the maximum depth range was $500 \mu \mathrm{m}$.

For nanoindentation measurements, all the coated samples were metallographically polished using $0.05 \mu \mathrm{m} \mathrm{Al}_{2} \mathrm{O}_{3}$ powder for $1 \mathrm{~h}$ followed by ultrasonic cleaning in acetone. This was adopted to minimize the effects of surface roughness on the nanoindentation measurements and to obtain consistent results. The root mean square (RMS) roughness of the polished samples was in the range $2-5 \mathrm{~nm}$ as measured by atomic force microscopy (see figure 1). For nanoindentation measurements, the sample was kept under optical microscope and a suitable area was chosen. Indentations were made on the desired area using a Berkovich diamond indenter at a load of $5 \mathrm{mN}$. Both the loading and unloading rates were set at $10 \mathrm{mN} / \mathrm{min}$. The maximum load was selected such that the indentation depth was about $1 / 10$ th of the coating thickness to eliminate the influence of the substrate (Tsui and Pharr 1999). Ten indentations were made on each sample to improve the accuracy of the measurements. The results reported herein represent averages of the group. For each loading/ unloading cycle, the load was plotted against the displacement of the indenter. The load/displacement curves were used to calculate the mechanical properties of the coatings.

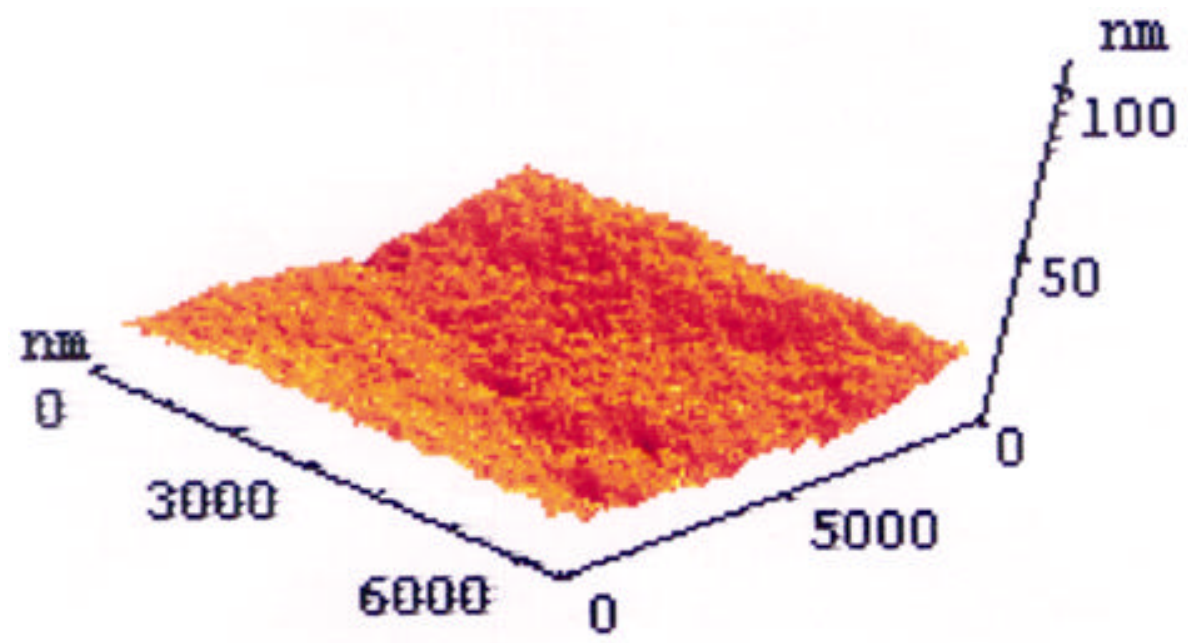

Figure 1. 3-Dimensional AFM image of a typical polished TiN coating showing RMS roughness of $\sim 4 \mathrm{~nm}$. 
Surface imaging of the as-deposited samples was carried out using atomic force microscopy. The maximum scan ranges for AFM in $X, Y$ and $Z$-directions were 20, 20 and $2 \mu \mathrm{m}$, respectively. The AFM resolution along the $X$, $Y$ and $Z$-axes was $<1 \mathrm{~nm}$. The combined optical/AFM system allows a specific sample area to be located under the optical microscope and then relocated precisely under the AFM in order to carry out high-resolution microscopy of the same area. The AFM was operated in non-contact mode with microfabricated silicon tip. In order to record AFM images of the samples very thin $(\sim 0.5 \mu \mathrm{m}$ thick) TiN coatings were deposited on silicon substrates at various substrate bias voltages (e.g. $0,-40,-80,-120,-160$, -200 , and $-240 \mathrm{~V})$. Other deposition conditions were kept same for all the samples. These coatings were imaged using AFM without polishing the samples so as to retain their original surface morphology. X-ray diffraction (XRD) data of the films, in glancing-angle geometry, were recorded in a Rigaku D/max 2200 powder diffractometer with thin film attachment. The X-ray source was a $\mathrm{CuK}_{\alpha}$ radiation $(\lambda=1.5418 \AA)$ and the glancing angle was $1^{\circ}$ for all the measurements.

\section{Results and discussion}

The load vs displacement curve was measured for all the samples. Typical plots obtained for four samples, deposited at different bias voltages, are shown in figure 2 . For the softest film, the maximum indentation depth was $150 \mathrm{~nm}$, which is less than 1/10th of the coating thickness. For the hardest film, the indentation depth was about $85 \mathrm{~nm}$. After initial contact of the indenter on surface, the load was increased at a predetermined rate $(10 \mathrm{mN} / \mathrm{min})$ to the desired maximum load $(5 \mathrm{mN})$ and then decreased at the same rate $(10 \mathrm{mN} / \mathrm{min})$ to zero. The unloading curve

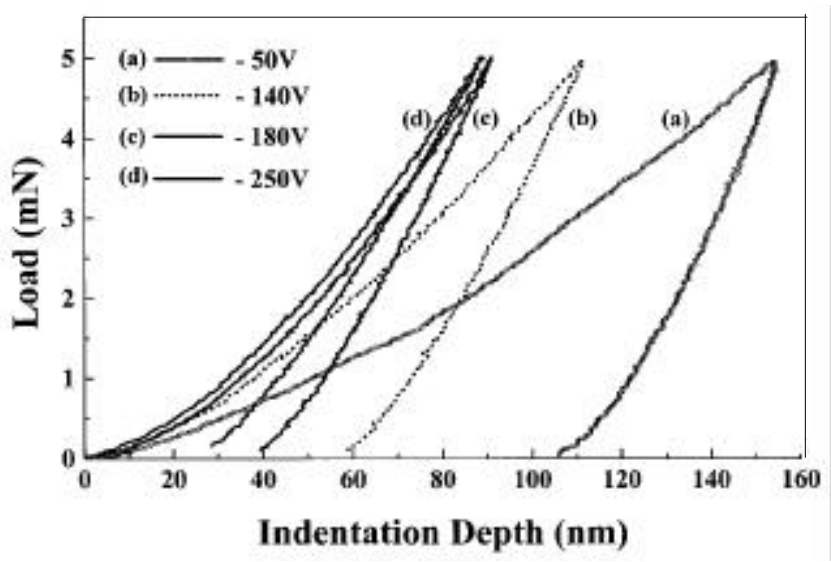

Figure 2. Load vs displacement curves for TiN coatings deposited at different bias voltages: (a) $-50 \mathrm{~V}$; (b) $-140 \mathrm{~V}$; (c) $-180 \mathrm{~V}$ and $(\mathrm{d})-250 \mathrm{~V}$. The sputtering power (220 watts) and nitrogen flow rate $(1.0 \mathrm{sccm})$ were kept same for all the samples. followed the partial elastic recovery of the sample material. From the load vs displacement plot, hardness $(H)$ was calculated using the method of Oliver and Pharr (1992), according to the relation:

$$
H=P_{\max } / A,
$$

where $P_{\max }$ is the peak indentation load and $A$ the indentation contact area, which was determined from the indenter shape function. In general, the loading data are influenced more by the plastic properties of the material and unloading data by the elastic properties. The hardness values were calculated from the loading portion of the curves.

In general, the hardness values measured by nanoindentation techniques are functions of surface roughness, chemical state of the surface layer and indenter size effect. The effect of surface roughness $(\sim 2-5 \mathrm{~nm})$ on the hardness value is expected to be very small since the surface roughness was less than 1/10th of the maximum penetration depth. At room temperature TiN does not have tendency to form oxide so it will not affect the indentation measurements. In order to minimize the effect of indenter shape function, the nanoindentation data were corrected with indenter calibration software. The applied load was $5 \mathrm{mN}$ for the nanoindentation measurements. For this load the maximum penetration depth was much lower than 1/10th of the coating thickness. Therefore, the measurements are not affected by the nature of the substrate. Furthermore, before making nanoindentation measurements on each sample the nanoindenter was calibrated with standard fused silica and high purity copper samples at 5 and $100 \mathrm{mN}$ loads, respectively. In these measurements vari-

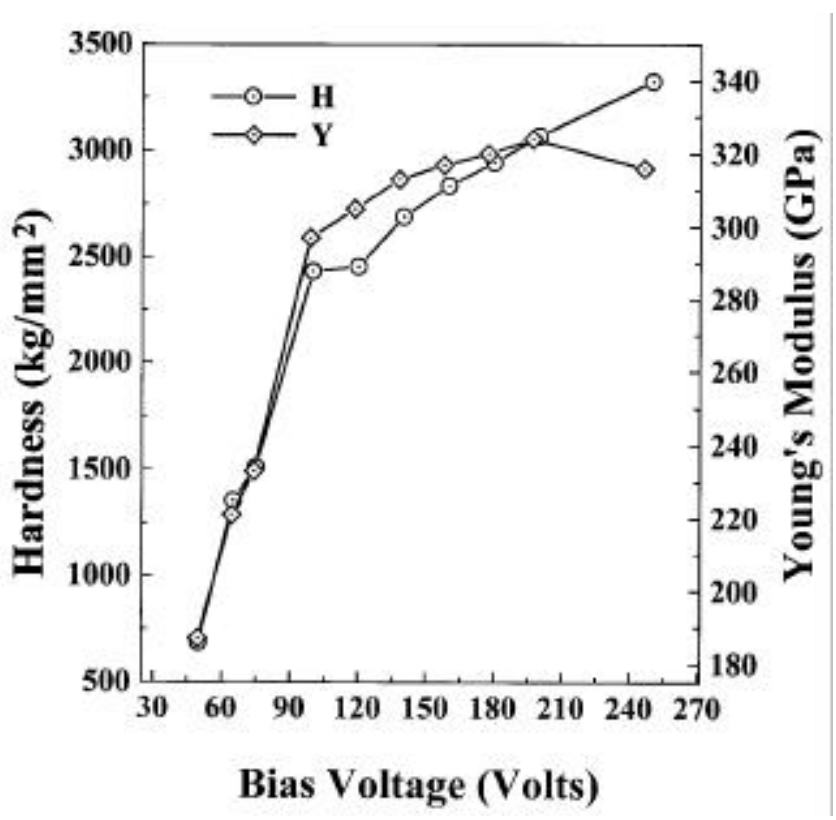

Figure 3. Variations of hardness and Young's modulus of TiN coatings with substrate bias voltage. 
ations of $\pm 3 \%$ from the standard values were observed. Considering all these, the hardness values reported herein, therefore, truly represent the actual hardness of the samples.

Figure 3 shows the variation of hardness with bias voltage for the samples prepared at a nitrogen flow rate of $1.0 \mathrm{sccm}$. The hardness increases with an increase in the bias voltage. The hardness of TiN coatings prepared at bias voltage $<-80 \mathrm{~V}$ is less than that of the bulk TiN $\left(1800 \mathrm{~kg} / \mathrm{mm}^{2}\right)$. But for samples prepared at biases between -100 to $-250 \mathrm{~V}$, the hardness is more than that of the bulk TiN and the maximum hardness $\left(3300 \mathrm{~kg} / \mathrm{mm}^{2}\right)$ is obtained at a bias voltage of $-250 \mathrm{~V}$. The ion current was of the order of $\sim 1 \mathrm{~mA} / \mathrm{cm}^{2}$ under these conditions. Results reported in the literature (Takahashi et al 2000; Zhengyang et al 2000) also indicate increase in the hardness of the TiN coatings with an increase in negative substrate bias and these are listed in table 1. The nanoindentation results of the present study are similar to those reported by Chou et al (2001) and Wang et al (2001), who report a nanoindentation hardness of 3000-3200 kg/ $\mathrm{mm}^{2}$ for TiN coatings deposited on silicon substrates. It can be seen from the table that most of the reported microindentation hardness values, however, differ considerably. The scatter in these results is likely due to the effect of the substrate on the hardness measurements. In addition, the microstructure and stoichiometry heavily depend on the deposition parameters (viz. substrate temperature, growth rate, nitrogen partial pressure and substrate bias), deposition process and preparation conditions. These factors greatly affect the mechanical properties of the coatings. Young's modulus $(Y)$ for the films was also calculated from the load vs displacement data using Oliver and Pharr (1992) method. Variation of Young's modulus with substrate bias is shown in figure 3. The Young's modulus increases with bias voltage. Large variations in the Young's modulus of TiN coatings with deposition parameters have been reported in the literature and these variations have been correlated with the microstructure of the coatings (Rouzaud et al 1995).

Our results show that biasing of the substrate plays an important role in modifying the mechanical properties of TiN films. It is expected that bias affects the ion current which in turn modifies the microstructure of the coatings. The effect of bias voltage on the ion current is shown in

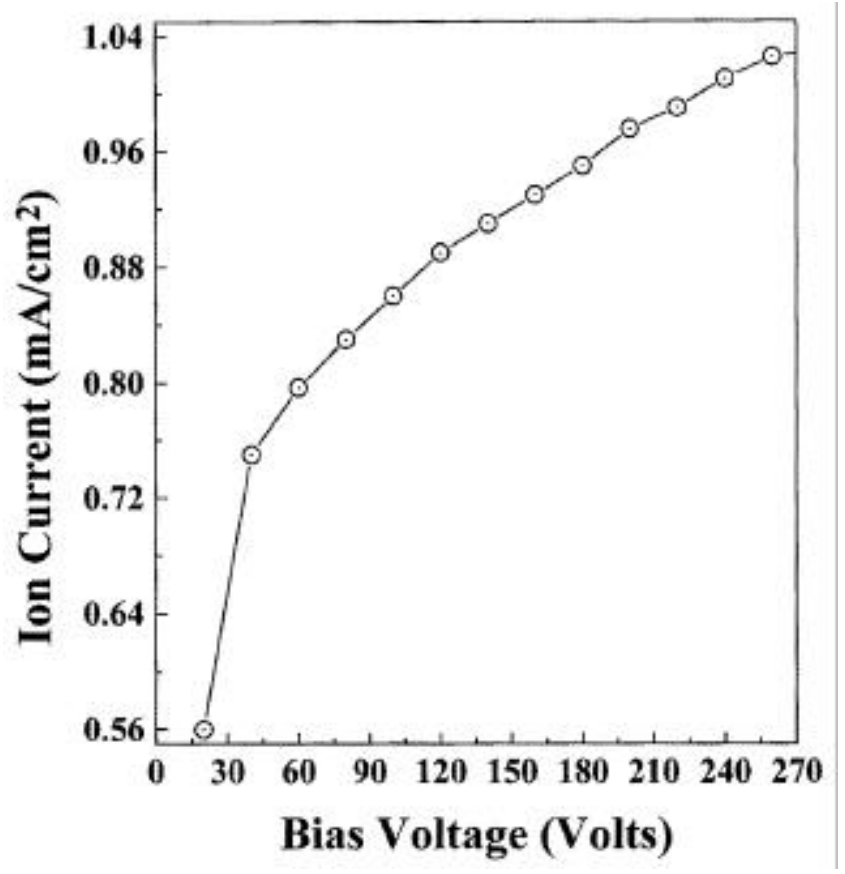

Figure 4. Variation of ion current with substrate bias voltage in $\mathrm{Ar}+\mathrm{N}_{2}$ plasma during reactive d.c. sputtering of TiN coatings. All the other process parameters, viz. operating pressure, nitrogen and argon flow rates, and sputtering power were kept same during the measurements.

Table 1. Hardness of TiN coatings obtained by various authors.

\begin{tabular}{|c|c|c|c|c|c|}
\hline Hardness $\left(\mathrm{kg} / \mathrm{mm}^{2}\right)$ & Substrate used & $\begin{array}{l}\text { Thickness } \\
\text { of coating } \\
\quad(\mu \mathrm{m})\end{array}$ & $\begin{array}{c}\text { Substrate } \\
\text { bias } \\
\text { used }(\mathrm{V})\end{array}$ & Deposition technique & Reference \\
\hline $3290(50 \mathrm{~g})$ & Cemented carbide & 5 & 150 & D.C. reactive magnetron sputtering & Sproul et al (1989) \\
\hline $4400 *(20 \mathrm{~g})$ & Steel & 3 & - & D.C. reactive magnetron sputtering & Musil et al (1986) \\
\hline $2300(15 \mathrm{~g})$ & Steel & 4 & - & Unbalanced magnetron sputtering & Yang et al (2000) \\
\hline $2900(0 \cdot 25 \mathrm{~N})$ & WC-Co & 4 & 200 & Triple-cathode vacuum arc deposition & Zhitomirsky et al (2000) \\
\hline $3500(10 \mathrm{~g})$ & High speed steel & $4 \cdot 5$ & 300 & Multi-arc ion plating & Zhengyang et al (2000) \\
\hline $3000(0 \cdot 50 \mathrm{~N})$ & Steel & 3 & 200 & Reactive ion plating & Takadoum and Bennani (2000) \\
\hline $2470(10 \mathrm{~g})$ & High speed steel & 5 & 100 & Unbalanced magnetron sputtering & Kadlec et al (1989) \\
\hline $3500(0 \cdot 25 \mathrm{~N})$ & Steel & 5 & 100 & RF magnetron sputtering & Matthes et al (1990) \\
\hline $2400(15 \mathrm{~g})$ & Copper & 1 & - & Electron beam evaporation & Subramaniam et al (2000) \\
\hline $2400 * *(?)$ & Steel & 3 & - & Unbalanced d.c. magnetron sputtering & Zhang and Hsieh (2000) \\
\hline $3000 * *(4 \mathrm{mN})$ & Silicon & $0 \cdot 5$ & 250 & Hollow cathode discharge ion plating & Chou et al (2001) \\
\hline $3200 * *(?)$ & Silicon & 0.5 & - & Pulsed laser deposition & Wang et al (2001) \\
\hline $3300 * *(5 \mathrm{mN})$ & Silicon & 2 & 250 & D.C. reactive magnetron sputtering & Present work \\
\hline
\end{tabular}

*Non-stoichiometric $\mathrm{TiN}_{x}$ films; **nanoindentation measurements. 
figure 4 . The ion current increases rapidly with bias voltage up to $-90 \mathrm{~V}$. Further increase in $V_{\mathrm{B}}$ results in marginal increase in the ion current $\left(\sim 0.9-1 \cdot 0 \mathrm{~mA} / \mathrm{cm}^{2}\right)$. Compari-
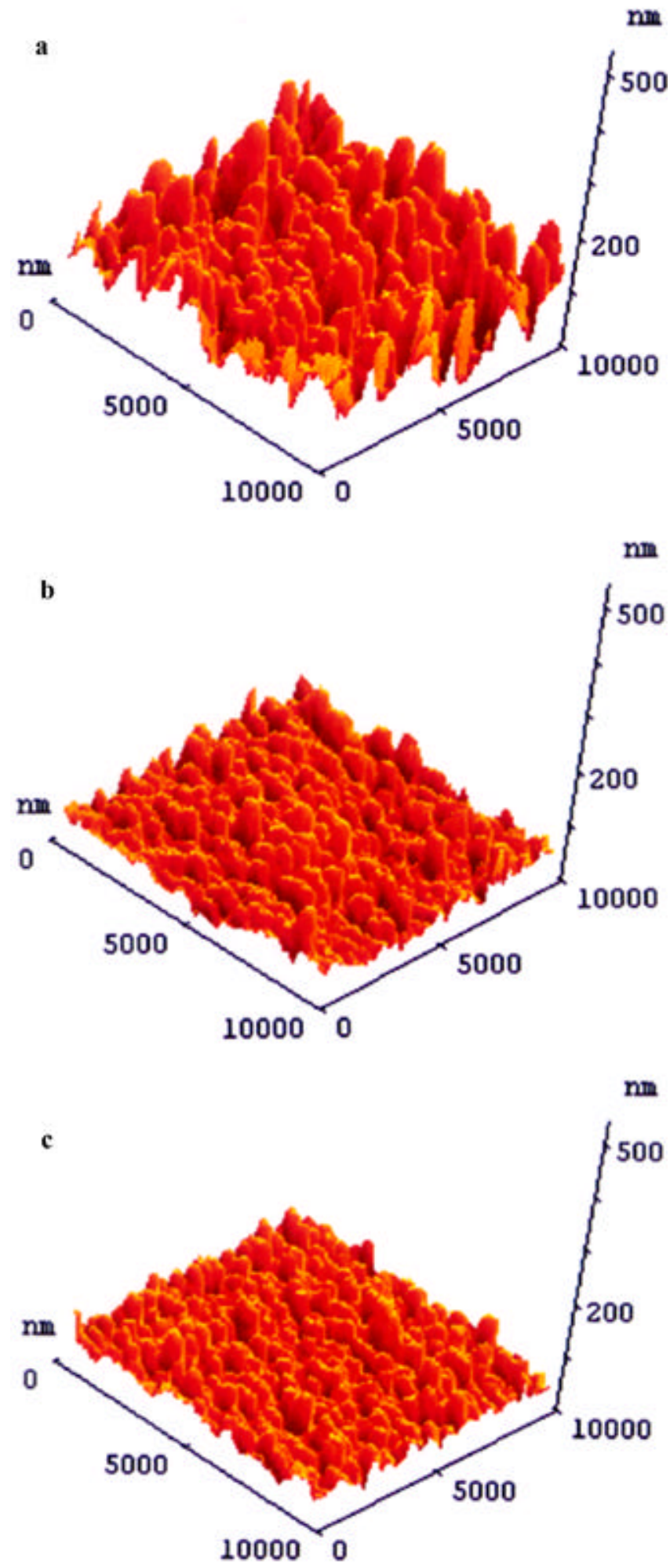

Figure 5. 3-Dimensional AFM images of $0.5 \mu \mathrm{m}$ thick TiN coatings deposited at various substrate bias voltages: a. $-40 \mathrm{~V}$, b. $-160 \mathrm{~V}$ and c. $-200 \mathrm{~V}$. son of figures 3 and 4 reveal that the hardness is proportional to ion current on the sample. As the substrate temperature during the deposition was low $\left(\sim 130^{\circ} \mathrm{C}\right)$ the enhancement in hardness of TiN coatings with substrate bias, in the present study, is attributed to ion bombardment of the coating as it is formed. Ion bombardment affects the grain size of the growing film. Biasing leads to higher nucleation density and consequently fine-grained morphology. The fine-grained morphology exhibits higher hardness. No biasing or lower values of substrate bias lead to coarse grains with high density of defect structure consisting of sub-grains and dislocation cell boundaries, and consequently lower hardness of the coatings. Furthermore, the energy imparted to the growing surface by ion bombardment helps to anneal out imperfections in the coating (Hultman et al 1987). But above a certain energy level, the effect of damage induced from the ion bombardment is more than that contributed by the annealing out of imperfections. Therefore, an optimum value of substrate bias is required to achieve better properties of the coatings. Very high bias voltage also results in high degree of compressive stresses. This is mainly because of incorporation of argon atoms in the coating. It is not very clear that whether the argon atoms produce the stresses by becoming trapped in the coating or by driving surface atoms into the coatings through an 'atomic peening' process.

Effect of ion bombardment on the grain size of TiN coatings has been confirmed by AFM studies. Three-dimensional surface morphologies of TiN coatings deposited at various bias voltages are shown in figure 5. It is interest-

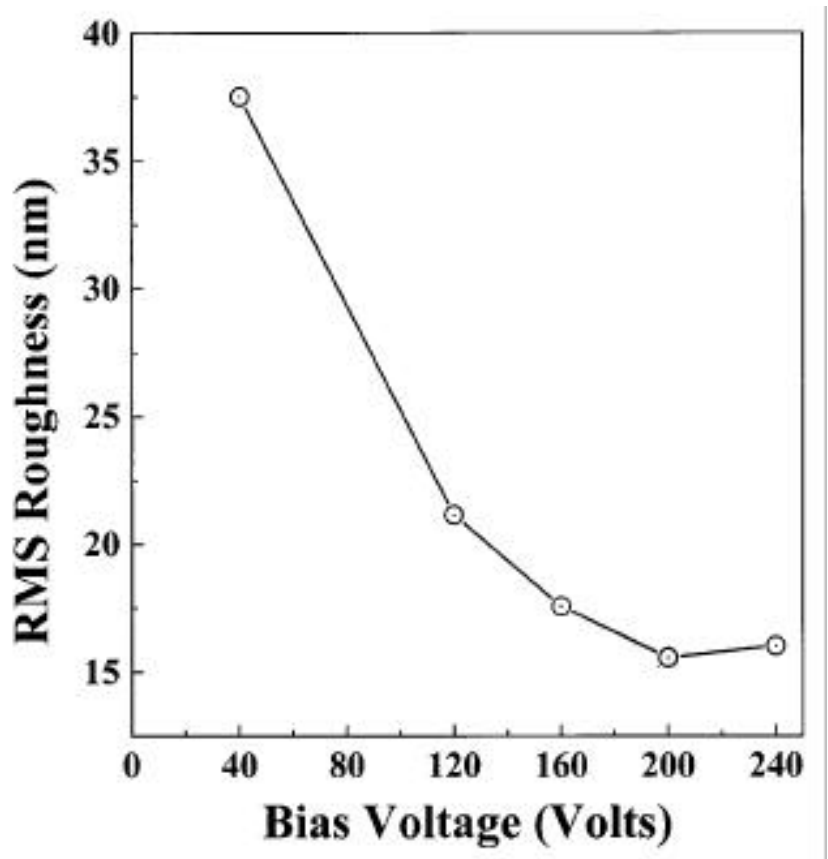

Figure 6. Variation of RMS roughness of $0.5 \mu \mathrm{m}$ thick TiN coatings with substrate bias voltage. 
ing to note that at lower bias voltage (i.e. $V_{\mathrm{B}}=-40 \mathrm{~V}$ ), the grain size was large and also the films were rough (RMS roughness $=\sim 38 \mathrm{~nm}$ ). However, as the bias voltage increased the grain size decreased. As shown in figure 6 the roughness was also low $(\sim 16 \mathrm{~nm})$ for films prepared at higher substrate bias $(-240 \mathrm{~V})$. Films prepared at $\left|V_{\mathrm{B}}\right| \leq 80 \mathrm{~V}$ were greyish, whereas films prepared at higher bias voltages exhibited shiny golden colour. The transition from grey to shiny golden colour correlates with an increase in hardness. For $\left|V_{\mathrm{B}}\right| \geq 250 \mathrm{~V}$, the film got delaminated partially during the deposition as the thickness increased. This may be due to the fact that sputtering of the film at higher substrate bias voltages induces high internal compressive stresses because of intense ion-irradiation. On the other hand, TiN films prepared at $\left|V_{\mathrm{B}}\right|=200 \mathrm{~V}$ exhibited excellent adhesion even on 3 inches diameter large aluminum and steel substrates. The titanium interlayer played a crucial role in improving the adhesion of TiN coatings. Poor hardness of the coating formed at $\left|V_{\mathrm{B}}\right|<80 \mathrm{~V}$ is due to porous and coarse microstructure, which in turn are attributed to low ad-atom mobility at lower bias voltages.

The nitrogen partial pressure also plays an important role in determining the mechanical properties of $\mathrm{TiN}$ coatings. Load vs displacement curves for four samples, deposited at different nitrogen flow rates, are plotted in figure 7 . The bias voltage for these samples was $-200 \mathrm{~V}$. The hardness increases by a factor of 3 as the nitrogen flow rate is decreased from $3.0 \mathrm{sccm}$ to $0.4 \mathrm{sccm}$ (see figure 8). Increase in hardness with a decrease in nitrogen flow rate is attributed to the fact that the film becomes more stoichiometric as the nitrogen flow is decreased. A proper ratio of $\mathrm{Ti} / \mathrm{N}$ is required to achieve stoichiometric TiN coating. Although, titanium nitride exists over a broad compositional range, 38.0-50.0 at.\% (Holleck 1986), stoichiometry of the film can significantly affect the composition of the coatings and hence the mechanical properties (Musil et al 1986; Sproul et al 1989; Yang et al 2000). Variation of Young's modulus with nitrogen flow is also plotted in figure 8 . The Young's modulus also changes with nitrogen partial pressure in a similar fashion. Nitrogen rich films show a rapid decrease in coating hardness and are greyish.

Finally, structure of all the coatings presented in this work was studied using X-ray diffraction. All the coatings showed (111) and (200) reflections of cubic TiN phase, however, the intensity and the full-width-at-halfmaximum (FWHM) varied with deposition parameters. For example, coating prepared at $-200 \mathrm{~V}$ substrate bias showed an FWHM of $0.688^{\circ}$ as compared to $0.541^{\circ}$ for the film deposited at no substrate bias. Broadening of the XRD peaks can be used to calculate average crystallite size of the coatings using well-known Scherrer equation. In the present study, the average crystallite size of TiN coatings deposited without and with a bias voltage of $-200 \mathrm{~V}$ was 162 and $126 \AA$. Therefore, crystallite size decreases

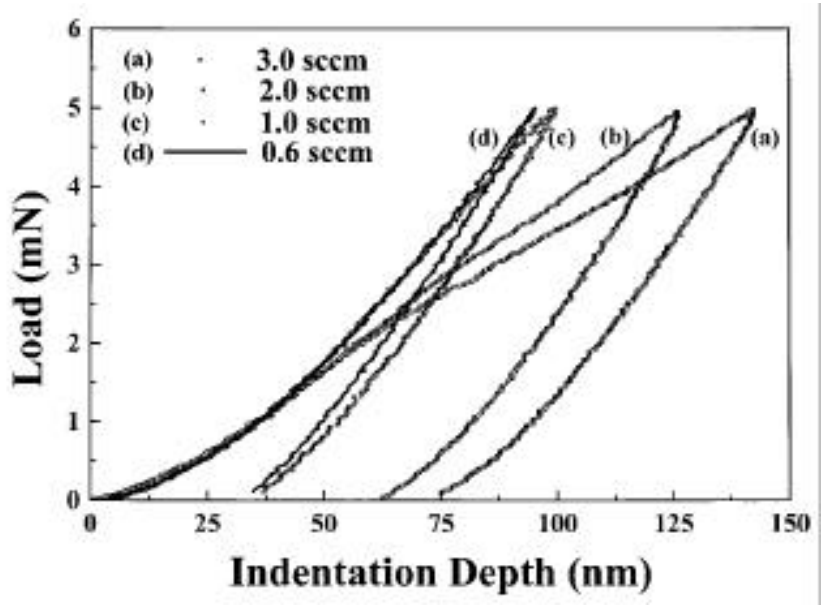

Figure 7. Load vs displacement curves for TiN coatings deposited at different nitrogen flow rates (a) $3.0 \mathrm{sccm}$; (b) $2.0 \mathrm{sccm}$; (c) $1.0 \mathrm{sccm}$ and (d) $0.6 \mathrm{sccm}$. The sputtering power (220 watts) and substrate bias $(-200 \mathrm{~V})$ were kept same for all the samples.

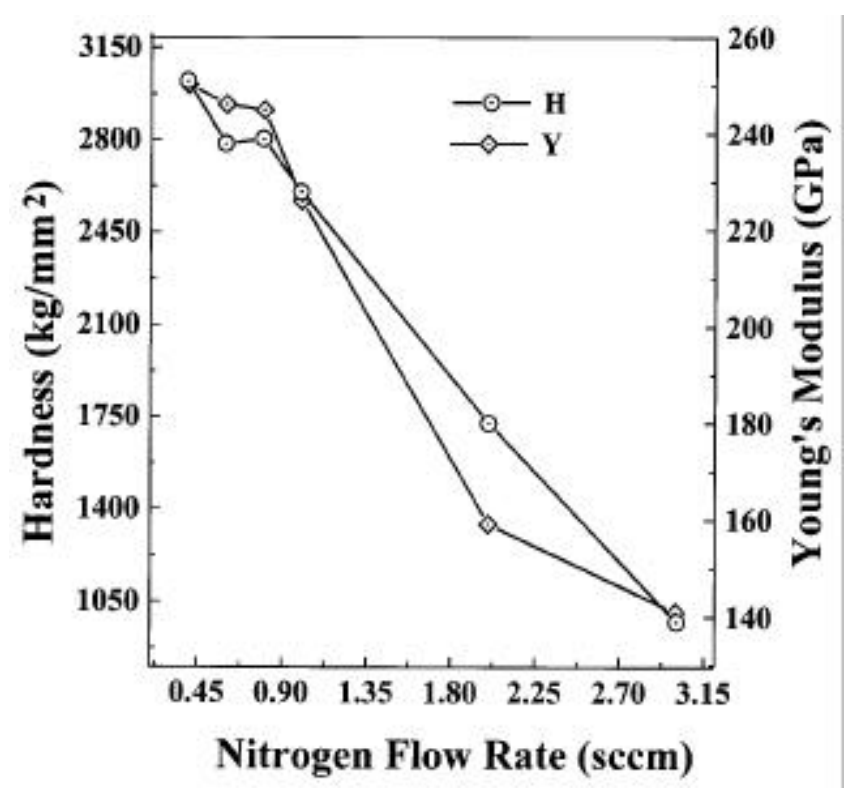

Figure 8. Variations of hardness and Young's modulus of TiN coatings with nitrogen flow rate.

with substrate bias and this observation is in good agreement with the AFM analysis, as discussed earlier.

\section{Conclusions}

The present study shows that substrate bias and nitrogen partial pressure greatly affect the mechanical properties and surface roughness of TiN coatings prepared by reactive d.c. magnetron sputtering process. Considerable increase in the nanoindentation hardness is observed when the substrate bias is increased from -100 to $-250 \mathrm{~V}$. Films deposited at $\left|V_{\mathrm{B}}\right|=250 \mathrm{~V}$ exhibit hardness as high 
as $3300 \mathrm{~kg} / \mathrm{mm}^{2}$, above which the films tend to have very low adhesion because of high compressive stress build up. Enhancement in the hardness of TiN coatings with substrate bias is attributed to fine-grained morphology of the coatings as a result of ion bombardment. Films prepared at lower nitrogen partial pressures are harder than those prepared at higher nitrogen partial pressures.

\section{Acknowledgements}

This work was supported by the Department of Science and Technology, New Delhi, and the Council of Scientific and Industrial Research, New Delhi.

\section{References}

Barshilia H C and Rajam K S 2002 Surf. Coat. Technol. 155195

Barshilia H C and Rajam K S 2003 Bull. Mater. Sci. 26233

Carney C and Durham D 1999 J. Vac. Sci. Technol. A17 2850

Chen Y M, Yu G P and Huang J H 2001 Surf. Coat. Technol. 141156

Chou W J, Yu G P and Huang J H 2001 Surf. Coat. Technol. 140206

Holleck H 1986 J. Vac. Sci. Technol. A4 2661

Hultman L, Helmersson U, Barnett S A, Sundgren J E and Greene J E 1987 J. Appl. Phys. 61552

Kadlec S, Musil J, Munz W D, Hakanson G and Sundgren J E 1989 Surf. Coat. Technol. 39/40 487
Matthes B, Broszeit E and Kloos K H 1990 Surf. Coat. Technol. 43/44 688

Musil J, Bardos L, Rajsky A, Vyskocil J, Dolezal B, Loncar G, Dadourek K and Kubicek V 1986 Thin Solid Films 136229

Oliver W C and Pharr G M 1992 J. Mater. Res. 71564

Petrov I, Hultman L, Helmersson U, Sundgren J E and Greene J E 1989 Thin Solid Films 169299

Randall N X, Schmutz C J and Soro J M 1998 Surf. Coat. Technol. 108-109 489

Rouzaud A, Barbier E, Ernoult J and Quesnel E 1995 Thin Solid Films 270270

Sproul W D, Rudnik P J and Graham M E 1989 Surf. Coat. Technol. 39/40 355

Subramanian C, Cavallaro G and Winkelman G 2000 Wear 241 228

Takadoum J and Bennani H H 1997 Surf. Coat. Technol. 96 272

Takahashi T, Masugata K, Kawai H, Kontani S and Yamamoto J 2000 Vacuum 59777

Tsui T Y and Pharr G M 1999 J. Mater. Res. 14293

Wang H, Sharma A, Kvit A, Wei Q, Zhang X, Koch C C and Narayan J 2001 J. Mater. Res. 162733

Yang S, Lewis D B, Wadsworth I, Cawley J, Brooks J S and Munz W D 2000 Surf. Coat. Technol. 131228

Zhang W H and Hsieh J H 2000 Surf. Coat. Technol. 130240

Zhengyang L, Wubiao Z, Yong Z, Guiying L and Eryan C 2000 Surf. Coat. Technol. 131158

Zhitomirsky V N, Grimberg I, Rapoport L, Boxman R L, Travitzky N A, Goldsmith S and Weiss B Z 2000 Surf. Coat. Technol. 133-134 114 